\title{
A TRADUÇÃO OU O ABSURDO DO POSSÍVEL: ON TRANSLATION DE PAUL RICOEUR
}

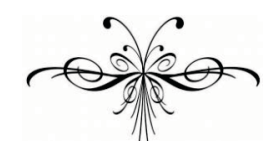

\section{CAROLINA PAGANINE}

\section{Resumo}

O presente artigo procura apresentar as principais idéias de Paul Ricoeur sobre tradução, contidas em seu livro On translation (2006), as quais, em última análise, lançam uma perspectiva positiva sobre os vários dilemas da tradução. Convergindo a teorização de outros pensadores sobre tradução e questões de linguagem, objetiva-se ressaltar o caráter intrinsecamente paradoxal da atividade tradutória, o que fundamenta a sua possibilidade de realização, isto é, pensar a tradução como uma tarefa que reside no "absurdo do possível".

Palavras-chave: tradução, possibilidade de tradução, absurdo do possível, paradoxo tradutório, Paul Ricoeur.

\begin{abstract}
This article seeks to present Paul Ricoeur's main idea on translation as exposed in his book $O n$ translation (2006) which ultimately views the various translation's dilemma in a positive perspective. By calling up theories of different thinkers on translation and on language issues, we aim at emphasizing translation's intrinsically paradoxical character, something that serves at the foundation of its own possibility of its achievement, that is, to think of translation as a task that lies in the "absurd of the possible".
\end{abstract}

Keywords: translation, translation possibility, absurd of the possible, translation paradox, Paul Ricoeur. 
$\mathrm{N}$ a fortuna teórica sobre tradução, um dos temas mais discutidos é o da impossibilidade da tradução. De maneira abreviada, a impossibilidade desta tarefa residiria na heterogeneidade semântica, sintática e histórico-cultural entre as línguas, o que impossibilitaria uma equivalência total entre texto original e texto traduzido. Partindo de um ponto de vista metafísico, a impossibilidade da tradução se baseia ou numa busca por uma tradução perfeita e definitiva, jamais alcançada por causa das perdas inevitáveis decorrentes da não-sobreposição entre as línguas, o que remonta ao mito de Babel - a existência de uma língua original e universal — ou à aspiração a uma língua pura, de acordo com o texto de Walter Benjamim, A tarefa do tradutor (Die Aufgabe des Übersetzers).

É a partir desses dois eixos que o pequeno livro de Paul Ricouer, On translation ${ }^{1}$, se abre para discutir vários conceitos caros aos Estudos da Tradução, sempre conferindo um ar positivo à questão (da possibilidade de tradução). Pois, ao contrário do que possa parecer, não é a impossibilidade que assombra tanto críticos e teóricos da tradução, mas sim a possibilidade em meio a (e apesar de) tantos dilemas lingüísticos e filosóficos. A tradução é uma dessas tarefas que reside no "absurdo do possível”, para usar uma expressão de Guimarães Rosa², e este livro de Paul Ricoeur sobre tradução nos dá algumas chaves para pensar a tradução desta maneira.

On translation (2006) é composto de três ensaios redigidos em momentos diferentes e publicados juntos em francês pela primeira vez em 2004, a saber "Translation as challenge and source of happiness", "The paradigm of translation" e "A 'passage': translating the untranslatable"3. As idéias que perpassam os três ensaios são convergentes e se sobrepõem; por isso, serão apresentadas conforme seus temas.

O ponto de partida para o primeiro ensaio é a interpretação que o autor francês faz do título do livro de Antoine Berman, L'épreuve de l'étrangert, em particular da palavra épremve, que, segundo Ricoeur, carrega o duplo sentido de "provação", isto é, passar por "dificuldade, situação aflitiva ou sofrimento muito grandes" 5, e de "experiência" que, neste contexto, representa um período de experimentação do estrangeiro impulsionado pelo desejo, pela vontade de traduzir ${ }^{6}$. Mas qual seria a provação/experiência ${ }^{7}$ pela qual o tradutor deve passar? Para responder a essa pergunta, o filósofo francês recorre aos conceitos freudianos sobre o recordar e o luto que encontrariam paralelo na tarefa do tradutor que, posicionado na corda bamba entre leitor e autor, também realiza os movimentos

\footnotetext{
${ }^{1}$ Tradução para o inglês de Eileen Brennan. Este trabalho utilizou a tradução inglesa. Todas as traduções para o português são da autora. Ciente da problemática que as "traduções de segunda mão" apresentam, as citações em inglês são oferecidas nas notas de rodapé.

${ }^{2}$ Cf. Rosa, João Guimarães. "Retábulo de São Nunca". In: Estas histórias. 5 ed. Rio de Janeiro: Nova Fronteira, 2001.

3 A saber: "Défi et bonheur de la traduction", "Le paradigme de la traduction", "Um 'passage': traduire l'intraduisible". In: Sur la traduction. Paris: Bayard, 2004.

${ }^{4} \mathrm{Em}$ inglês The test of the foreign e na tradução brasileira A prova do estrangeiro (2002).

${ }^{5}$ Dicionário Eletrônico Houaiss da Língua Portuguesa.

${ }^{6}$ Cf. Ricoeur, 2006, p. 3.

7 O uso conjunto dos dois termos - "provação/experiência" se justifica na medida em que mantém exposta ao leitor a dualidade conceitual presente em epréuve e test.
} 
de salvaguardar sua língua e aceitar a perda ao lidar com os sistemas lingüísticos e os textos. Segundo Ricoeur, "é nesta posição incômoda de mediador [entre leitor e autor] que se encontra a provação/experiência em questão" 8 .

Esta posição de mediador também é o ponto de partida para as várias dualidades que atravessam a atividade tradutória e que assumem, para Ricoeur, a forma de um paradoxo. O filósofo cita o exemplo dado por Franz Rosenzweig, para quem a tradução é como servir a dois patrões — o autor estrangeiro e o leitor com seu desejo por apropriação — e, também, os dois métodos propostos por Schleiermacher ${ }^{9}$, cujo paradoxo pode ser compreendido nas seguintes máximas: "levar o leitor ao autor", "trazer o autor até o leitor". De outra maneira, Sebastião Uchoa Leite coloca o paradoxo da tradução comparando-o com o trabalho do ator e segundo uma perspectiva do texto: "Tal como o ator é outro sendo ele mesmo, o tradutor cria um duplo do texto que é outro e tem de ser o mesmo. É o paradoxo da tradução, dividida entre ser criação e ser interpretação" (1995, p. 9).

Esses paradoxos devem ser entendidos diferentemente dos paradoxos lógicos, mais preocupados com a veracidade ou falsidade das conclusões de suas premissas, conclusões que estabelecem a contradição e resultam na exclusão das demais alternativas. Já nos paradoxos da tradução, as duas premissas (i. e. autor e leitor, texto original e tradução) são consideradas concomitantemente admissíveis, de maneira que a contradição acaba por tornar-se constitutiva da própria atividade tradutória.

Dito de outra maneira, os paradoxos da tradução revelam que há uma tensão entre autor e leitor, texto original e tradução, com a qual o tradutor deve contemporizar. Como expôs Sebastião Uchoa Leite, poderíamos dizer que essa tensão reflete-se no fato de que a tradução deve ser um outro texto (assimilável pelo leitor estrangeiro) ao mesmo tempo em que é o mesmo texto (representante da obra do autor original). Há aí uma aparente contradição entre os dois focos, mas que na prática não são excludentes, pois o leitor e tradutor desde sempre compactuam na ilusão da tradução funcionando como o próprio texto original.

O absurdo dessa condição também põe em choque outras dualidades presentes quando se fala em tradução, quais sejam, a oposição entre conteúdo e forma e entre texto original e tradução. Para Henri Meschonnic, estas oposições foram historicamente construídas: "Estas noções acabam por opor texto e tradução, por meio de uma sacralização da literatura. [...] Desse jogo de oposição ideológica entre texto e tradução resulta uma noção metafísica, não historicizada, a noção do intraduzível” (1980, p. 82).

Mas o que seria o "intraduzível"? Ainda segundo Meschonnic, o intraduzível é um produto social e histórico que se passa "por uma natureza, um absoluto" (Idem). Nas palavras de Antoine Berman, o intraduzível é um valor, valor de "auto-afirmação" de um texto, isto é, de seu alto grau poético (2007, p. 40). Sobre esse tema, Ricoeur mostra, sem corroborar, que a idéia do intraduzível como absoluto é fundamentada na hipótese de Sapir-Whorf que acentua o caráter

\footnotetext{
8 "It is in this uncomfortable position of mediator that the test in question lies" (2006, p. 4).

${ }^{9}$ Cf. Schleiermacher, Friedrich. "Sobre os diferentes métodos de tradução". Trad. Margarete Von Mühlen Poll. In: Clássicos da teoria da tradução. Werner Heidermann (org.). Florianópolis: UFSC, Núcleo de Tradução, 2001. Em especial, p. 43-67.
} 
radicalmente dessemelhante entre as línguas, o que, por sua vez, produziriam realidades sociais e visões de mundo radicalmente diferentes (2006, p. 14-15). Diante dessa diferença radical entre as línguas, a qual pressupõe uma impossibilidade absoluta da tradução, Ricoeur, em contrapartida, propõe a idéia de "segmentos de intraduzibilidade" que, espalhados pelos textos, seriam responsáveis por fazer da tradução uma tarefa penosa e condenada à insatisfação. Isso aconteceria devido a não-sobreposição total dos campos semânticos, sintáticos, dos estilos e até das relações de conotação e denotação dos sistemas lingüísticos. Assim, em vez de uma intraduzibilidade absoluta entre as línguas, teríamos uma "intraduzibilidade intermitente" (2006, p. 5-6).

Porém, no terceiro ensaio, Ricoeur relaciona a questão do intraduzível com a propensão da língua para o indizível, para o enigma, o segredo: "A luta de qualquer língua com o secreto, o escondido, o mistério, o inexpressável é, acima de tudo, o incomunicável mais arraigado, o intraduzível inicial" ${ }^{10}$. Também para Mário Laranjeira o intraduzível está relacionado, de início, ao indizível, isto é, "o indizível é o intraduzível intralingüístico, a impossibilidade ou a incapacidade de significar (traduzir em signos) lingüísticamente uma realidade, um conceito, um sentimento, uma emoção" (2003, p. 23). Este espaço entre o que se pensa e o que se fala remete à visão de Humboldt sobre a linguagem, para quem a língua é "um mundo situado no espaço intermediário entre o mundo externo, aparente, e o mundo interno que age em nós" (2006b, p. 9). Isso pressupõe, ainda segundo Humboldt, tomar a linguagem como mediadora, primeira e privilegiadamente, do entendimento do ser humano sobre sua própria realidade ("o cerne da ação intelectual") e, depois, como ato comunicativo ("designar objetos e mediar o entendimento", 2006a, p. 95). É nesse espaço entre pensamento e palavra que residiria a luta (a tradução) para se dizer o que não se sabe como dizer, o inefável, o intraduzível inicial que, por sua vez, levaria ao intraduzível entre as línguas. E é aqui também que surge a capacidade de reflexão da linguagem sobre si mesma e que origina, em última instância, a capacidade da linguagem para o ficcional.

É sabido que os grandes escritores trabalham muitas vezes com o não-dito, com o que é sugerido, e até mesmo com a omissão e com o silêncio. Benedito Nunes, escrevendo sobre Clarice Lispector, evoca esse espaço intermediário ao afirmar que, em seus livros, a autora é capaz de levar a experiência da linguagem "ao seu último limite, à sua extrema conseqüência, do confronto decisivo entre realidade e expressão" (2009, p. 132, grifo meu). Logo à frente, Nunes conclui que essa experiência "é uma forma de dirigir a linguagem para além dela mesma, isto é, para o inexpressado, o absoluto, o abismo do ser primordial" (Idem).

Voltando aos paradoxos, estes carregam em si, junto com as dualidades a que fazem referência, a suposição da impossibilidade da tradução, mais especificamente, a impossibilidade de uma tradução perfeita e definitiva. Quanto a isso, Ricoeur se vale da teorização de Freud sobre o trabalho do luto para aconselhar os tradutores a "abandonar o ideal da tradução perfeita" 11 , entendendo o luto como a capacidade dos seres humanos de superarem uma perda, seja ela referente a um ente querido, a um objeto ou a alguma abstração.

\footnotetext{
10 "Every language's struggle with the secret, the hidden, the mystery, the inexpressible is above all else the most entrenched incommunicable, initial untranslatable" (2006, p. 33).

11 “[...] [to] give up the ideal of the perfect translation" (2006, p. 8).
} 
Embora advirta aos tradutores que renunciem à idéia de uma tradução perfeita, para Ricoeur, a busca por este ideal teria "encorajado a ambição de revelar a face oculta da língua de partida da obra a ser traduzida e, vice-versa, a ambição de des-provincializar a língua materna, que é convidada a se pensar como uma língua entre outras e, por fim, se ver como estrangeira"12. Ricoeur ainda relaciona o sonho da tradução perfeita à aspiração messiânica por uma língua pura, como demonstrado por Walter Benjamim em A tarefa do tradutor. Entretanto, o autor francês não corrobora a argumentação da língua pura, e nem a da existência de uma língua universal, como justificativa para a impossibilidade absoluta da tradução. Em seguida, Ricoeur conclui que:

o sonho por uma tradução perfeita se equivale ao desejo de que a tradução tenha ganhos, ganhos sem perdas. É precisamente por este ganho sem perda que devemos estar de luto até que cheguemos a uma aceitação da diferença intransponivel entre o próprio e o estrangeiro. ${ }^{13}$

A felicidade associada ao ato de traduzir reside, portanto, na percepção do caráter irredutível e dialógico das partes, o próprio e o estrangeiro, o que leva à aceitação de outra irredutibilidade proposta pelo autor francês, a da "equivalência sem adequação"14. Entendemos, assim, que Ricoeur propõe um grau de correspondência entre texto original e texto traduzido que não pressupõe uma adequação total, isto é, uma identidade absoluta, entre os textos. É a partir dessas premissas de aceitação que Ricoeur apresenta seu conceito de hospitalidade lingüistica: "A hospitalidade lingüística, então, onde o prazer de habitar a língua do outro é equilibrado pelo prazer de receber a palavra estrangeira em casa, em seu próprio lar acolhedor" 15.

Nota-se aqui uma influência da teorização de Antoine Berman a respeito da tradução ética, que é "animada pelo desejo de abrir o Estrangeiro enquanto Estrangeiro ao seu próprio espaço de língua" (2007, p. 69, grifo do autor). O 'lar acolhedor' de que fala Ricoeur é semelhante ao 'albergue do longínquo' de Berman, isto é, um espaço plural, avesso a totalizações e a apropriações deformadoras (da língua, da cultura, da poeticidade). Dessa maneira, também vemos no pensamento de Ricoeur a dimensão ética do traduzir, na medida em que o tradutor responde a uma dupla fidelidade: "Levar o leitor ao autor, trazer o autor até o leitor, ao risco de servir e de trair dois patrões: isto é praticar o que eu chamo de hospitalidade lingüistica"16. Ao

\footnotetext{
12 " [...] it has encouraged the ambition of revealing the hidden face of the source language of the work to be translated and, vice versa, the ambition of de-provincialising the mother tongue, which is invited to think of itself as one language amongst others, ultimately to see itself as foreign" (2006, p. 8-9, grifo do autor).

13 “....] the dream of the perfect translation amounts to the wish that translation would gain, gain without losing. It is this very same gain without loss that we must mourn until we reach an acceptance of the impassable difference of the peculiar and the foreign" (2006, p.9).

14 “equivalence without adequacy" (2006, p.10).

15 "Linguistic hospitality, then, where the pleasure of dwelling in the other's language is balanced by the pleasure of receiving the foreign word at home, in one's own welcoming house" (2006, p.10).

16 "Bringing the reader to the author, bringing the author to the reader, at the risk of serving and of betraying two masters: this is to practice what I like to call linguistic hospitality" (2006, p. 23, grifo do autor).
} 
fim, reconhecemos que os paradoxos que tão notadamente descrevem o dilema do tradutor se configuram como o próprio meio de expressão do absurdo do possível.

No segundo ensaio, a possibilidade da tradução é retomada sob a perspectiva de duas definições para a tarefa: a primeira, de sentido restrito, seria a tradução interlingüística, isto é, de uma língua para outra; já a segunda, de sentido amplo, se referiria à interpretação de quaisquer significados dentro de uma mesma comunidade, o que Jakobson chamou de tradução intralingüística e que, de outro modo, George Steiner, apud Ricoeur, epitomou na frase "compreender é traduzir", refletindo o paradigma hermenêutico proposto por Gadamer ${ }^{17}$.

Considerando a tradução interlingüística, Ricoeur primeiro traz à tona a questão da multiplicidade de línguas, mola originária propulsora da atividade tradutória. Essa multiplicidade lingüística apresentaria, segundo Ricoeur, duas alternativas sobre a (im)possibilidade da tradução: ou a tradução é impossível dada a radicalidade da diferenças entre as línguas, ou a tradução é possível através de uma reconstrução da língua original, cuja existência permitiria as semelhanças, os encontros semânticos entre línguas diferentes.

Ainda que não haja explicação definitiva para compreender a utilidade e a razão de existirem tantas línguas, o fato é que as pessoas sempre traduziram. Essa capacidade dos seres humanos de aprenderem a se comunicar em uma língua diferente da materna é a revelação positiva que se tem ao examinar o mito de Babel $^{18}$, cujo castigo imposto de "dispersar e confundir" é costumeiramente interpretado como uma "catástrofe lingüística irremediável"19.

Entretanto, é na reinterpretação positiva que Ricoeur faz do mito de Babel que encontramos sua contribuição para a possibilidade da tradução como uma tarefa pertence ao "absurdo do possível", ou nas palavras do filósofo francês, ao "apesar de tudo": "Apesar da heterogeneidade dos idiomas, existem pessoas bilíngües, poliglotas, intérpretes e tradutores" 20 . De fato, é com o surgimento da multiplicidade de línguas que surge a tradução. Para Ricoeur, a dispersão e a confusão das línguas, desencadeadas pela queda da torre de Babel, estão no âmago do exercício da linguagem. Isto é, em meio ao entendimento que a linguagem

17 Sobre as relações entre tradução, interpretação e compreensão, segundo a perspectiva hermenêutica de Gadamer, conferir Paganine, Carolina. "Tradução e interpretação: uma perspectiva hermenêutica". In: Scientia Traductionis. Número 3. Nov/2006. <http://www.scientiatraductionis.ufsc.br/hermeneut.pdf> Acc.: 05 fev 2010.

18 Sobre a história da torre de Babel, Suzana Kampff Lages conta que "segundo a interpretação tradicional do relato bíblico, a criação de múltiplas línguas se deu em decorrência do castigo de Deus para o desejo de onipotência do homem, que aspirava, por meio da construção da torre, alçar-se às mesmas divinas alturas, ou seja, pretendia disputar o lugar de autoridade de Deus. Do ponto de vista da história e da teoria da tradução, pois, in principio fuit Babel: confusão, introdução da multiplicidade, da diferenciação no seio de uma desejada, suposta, plenitude lingüística originária” (p. 29-30, grifo da autora). In: Walter Benjamin: tradução e melancolia. São Paulo: Edusp, 2007.

19 “an irremediable linguistic catastrophe" (2006, p. 12). Ricoeur usa esta expressão em sua contextualização da questão da diversidade das línguas.

20 "Despite the heterogeneity of idioms, there are bilinguals, polyglots, interpreters and translators" (2006, p. 18). 
propicia, há sempre um grau de não-entendimento ou de entendimento relativo ${ }^{21}$. Em sua releitura do mito, o filósofo mostra que a dispersão e a confusão das línguas não necessariamente foram algo ruim, mas sim um fato da vida, "o reconhecimento não condenatório de uma separação original"'22 .

Mais uma vez, a teorização de Ricoeur sobre a tradução nos mostra que a tradução tem seus fundamentos na possibilidade, inclusive em sua interpretação do mito de Babel. Portanto, a conseqüência da queda da torre - a multiplicidade de línguas — não torna a tradução impossível, mas é sim a causa e a possibilidade de seu acontecimento. Indo além, poderíamos ver a tradução sempre como uma possibilidade, seja de interpretação ou compreensão de um texto, seja de renovação das línguas envolvidas ou de sobrevida da obra literária.

Ao pensar a tradução como possibilidade, Ricoeur abre caminho para interpretar os dilemas que a tradução coloca sob outra perspectiva. O filósofo francês sugere que se substitua a alternativa teórica de "traduzível versus intraduzível" pelo binômio, de cunho prático, "fidelidade versus traição". No entanto, adotar este binômio "significa admitir que a prática de tradução permanece sendo uma operação arriscada que está sempre em busca de sua teoria" 23 .

Nessa operação arriscada, a equivalência é apenas presumida e "não fundamentada em uma identidade de significados demonstrável. Uma equivalência sem identidade. Essa equivalência pode apenas ser almejada, trabalhada, presumida" 24 . Em seu artigo sobre On translation, Ivone Benedetti se volta em especial para a questão da identidade, apresentando três alternativas diferentes para se definir o que é a identidade e em que medida elas seriam aplicáveis à atividade tradutória ${ }^{25}$. Após balizar e exemplificar as três alternativas, mostrando que cada tipo de texto (i.e. literário, jurídico, científico) e cada contexto (i.e. da cultura, do lugar, da época) influenciam na escolha do tipo de identidade a ser trabalhado entre texto original e tradução, a autora conclui que "não estamos aí diante de um problema de intraduzibilidade, mas de um problema de estabelecimento de critérios para a identidade em traducão" (2006, p. 41, grifo da autora). Para Benedetti, esses critérios são mais facilmente estabelecidos em textos técnico-científicos, em que os vocábulos da língua de partida e da língua de chegada se correspondem em relação à coisa referida (i.e. em um texto sobre transplantes, "kidney" necessariamente corresponderá a "rim"). Os textos literários, no entanto, principalmente os poéticos, costumam diluir esta relação entre a palavra e a coisa referida, além de se utilizarem de outras estratégias lingüísticas criativas. Chegamos, então, a uma conclusão já bastante aceita na comunidade tradutória: não há soluções prontas ou modelos universalmente

21 Cf. Heidermann, Werner. Humboldt: linguagem, literatura e bildung. Introdução. Werner Heidermann, Markus J. Weininger (orgs.). Florianópolis: UFSC, 2006, p. XXX.

22 “[...] the non-judgemental acknowledgement of an original separation" (2006, p. 18).

23 "....] it means admitting that the practice of translation remains a risky operation which is always in search of its theory" (2006, p. 14).

24 "[...] not founded on a demonstrable identity of meaning. An equivalence without identity. This equivalence can only be sought, worked at, supposed" (2006, p. 22, grifo do autor).

25 Os três conceitos de identidade apresentados por Benedetti são o conceito aristotélico de unidade, o conceito leibniziano de igualdade e a concepção de convencionalidade de F. Waismann (2006, p. 37-40). 
aplicáveis à tarefa do tradutor. Qualquer tradução, especialmente a literária, requer sempre uma abordagem específica às muitas e complexas variáveis que influenciam e determinam o trabalho do tradutor.

O fato de não haver modelos absolutos para guiar a atividade tradutória na busca de seu objetivo de ser fiel não quer dizer que não possamos avaliá-la. De acordo com Ricoeur, a tarefa de traduzir está sempre sujeita ao confronto/encontro com outras e novas traduções, sendo as retraduções a melhor maneira de se criticar uma tradução: "E a única maneira de se criticar uma tradução - algo que podemos sempre fazer — é sugerindo uma outra tradução que seja presumida ou pretensamente melhor ou diferente" 26 . Os exemplos ideais de retradução, segundo o filósofo, seriam aqueles dos grandes clássicos da literatura - Odisséia, Dom Quixote, A divina comédia - sucessivamente retraduzidos ao logo do tempo e, portanto, geradores daquela equivalência sem identidade.

Além disso, para se trabalhar com equivalência em tradução, é importante saber também que, para Ricoeur, os tradutores trabalham com textos, e não com palavras ou orações. Portanto, a equivalência não deve ser compreendida a partir de uma visão atomizada sobre a linguagem, mas sim no seu aspecto textual e contextual, em que as visões de mundo e os referenciais culturais e históricos do texto exercem grande influência sobre os aspectos especificamente lingüísticos (se é que é possível separá-los). É assim que Ricoeur conclui com grande propriedade que

[...] o trabalho do tradutor não se move da palavra para a oração, para o texto, para o grupo cultural, mas sim ao contrário: ao absorver vastas interpretações do espírito de uma cultura, o tradutor volta novamente para o texto, para a oração e para a palavra. ${ }^{27}$

A idéia de que o trabalho do tradutor parte, inicialmente, do texto nos remete à proposta de Meschonnic de que as traduções se relacionam entre texto e texto e não de língua para língua, arrematando que "a relação interlingüística é que advém da relação intertextual e não a relação intertextual que advém da relação interlingüística" (1980, p.86). É neste mesmo sentido que Ricoeur considera a natureza da equivalência como um produto da tradução e não como um de seus pressupostos. Ou seja, a equivalência não existe a priori entre os sistemas lingüísticos, mas é sim através de traduções que as equivalências se constroem e se estabelecem.

Como a equivalência passa a ser vista em termos não absolutos - o que temos, segundo Ricoeur, é uma equivalência sem identidade —, a idéia de uma tradução perfeita também é relativizada. Desistir deste sonho, reconhecendo a diferença intransponível entre o próprio e o estrangeiro, é, para Ricoeur, a verdadeira "prova do estrangeiro" (2006, p. 23). Vemos aqui que os paradoxos que descrevem a tradução são a voz de um outro paradoxo, o absurdo do possível. Absurdo, pois colocam a tradução como um projeto irrealizável, um sonho que -

\footnotetext{
26 "And the only way of criticizing a translation - something we can always do - is to suggest another supposed, alleged, better or different one” (2006, p.22).

27 " [...] the work of the translator does not move from the word to the sentence, to the text, to the cultural group, but conversely: absorbing vast interpretations of the spirit of a culture, the translator comes down again from the text, to the sentence and to the word" (2006, p. 31).
} 
no entanto - é diariamente possível, realizável e, muitas vezes, com grandes méritos.

Os ensaios de Ricoeur, ainda que sejam vistos como inconclusivos nas questões que propõem ao leitor ou, então, avesso a prescrições sobre a prática do traduzir, lançam uma luz positiva - a luz do possível - sobre os velhos e bastante discutidos dilemas da tradução. Afinal, a atividade tradutória é fonte de desafio e alegria, como diz um dos títulos dos ensaios. Além disso, o pensamento de Ricoeur faz convergir múltiplas perspectivas sobre questões de linguagem e de tradução — Berman, Steiner, Humboldt —, levando o leitor interessado a se aprofundar nos temas tratados por esses autores, sempre tão ricos e controversos.

Ao final, percebemos que Ricoeur não oferece respostas fáceis para a situação paradoxal da atividade tradutória e nem para seus problemas, como a questão da fidelidade, da equivalência e da intraduzibilidade intermitente, mas propõe uma nova perspectiva para que os tradutores possam trabalhar em meio às dificuldades e, ao fim, ficarem satisfeitos com os resultados. O conselho último de Ricoeur, de renunciar ao sonho da tradução perfeita — o que significa aceitar a prova do estrangeiro e se equilibrar nos paradoxos da tradução que exigem uma dupla fidelidade - impele, nós tradutores, assim como os personagens de Clarice Lispector, a aderir "ao Absurdo, aceitando as contradições da existência" (Nunes, 2009, p. 132)..$^{28}$

28 A autora agradece a Gustavo Althoff pela leitura atenta da primeira versão deste artigo e ao parecerista anônimo da Revista pelas valiosas sugestões. 


\section{Referências}

BENEDETTI, Ivone C.. "Da (in)traduzibilidade: a propósito de Paul Ricoeur". In: TradTerm. Número 12. 2006. p. 36-54. $<$ http://ivonecbenedetti.files.wordpress.com/2009/10/paul-ricoeur-sur-latraduction0001.pdf> Acesso em: 29 jan. 2010.

BERMAN, Antoine. A prova do estrangeiro: cultura e tradução na Alemanba romântica. Trad. Maria Emília Pereira Chanut. Bauru: EDUSC, 2002. - A tradução e a letra on o albergue do longinquo. Trad. Andréia Guerini, Marie-Hélène C. Torres \& Mauri Furlan. Rio de Janeiro : 7letras/PGET, 2007.

HUMBOLDT, Wilhelm von. "Forma das línguas". Trad. Karin Volobuef. In: Humboldt: linguagem, literatura e bildung. Werner Heidermann, Markus J. Weininger (orgs.). Florianópolis: UFSC, 2006a. p. 94-119.

- "Sobre a natureza da linguagem em geral". Trad. Paulo Sampaio Xavier de Oliveira. In: Humboldt: linguagem, literatura e bildung. Werner Heidermann, Markus J. Weininger (orgs.). Florianópolis: UFSC, 2006b. p. 2-19.

LARANJEIRA, Mário. "A tradução interlingual do poema". In: Poética da tradução: do sentido à significância. 2 ed. São Paulo: Edusp, 2003. p. 23-43.

LEITE, Sebastião Uchoa. "O paradoxo da tradução poética: notas sobre o pequeno e o grande jogo na poesia de François Villon". In: Jogos e Enganos. Rio de Janeiro: 34/UFRJ, 1995. p. 9-46.

MESCHONNIC, Henri. "Propostas para uma poética da tradução". trad. Luísa Azuaga. In: A tradução e seus problemas. Org. Jean-René Ladmiral. São Paulo: Martins Fontes, 1980. p. 79-87.

NUNES, Benedito. "Linguagem e silêncio". In: $O$ dorso do tigre. 3 ed. São Paulo: 34, 2009. p. 125-134.

RICOEUR, Paul. On translation. Trad. Eileen Brennan. New York: Routledge, 2006. 